\title{
PAPER SUBSTRATES FOR INKJET PRINTING OF UHF RFID ANTENNAS
}

\author{
Juraj Gigac, Mária Fišerová, Maroš Kováč, Monika Stankovská \\ Pulp and Paper Research Institute Bratislava \\ Slovak Republic \\ (Received May 20I9)
}

\begin{abstract}
Conventional papers are not suitable for printed electronics because they have a rougher surface than the plastic film commonly used for electronics printing. The paper surfaces were modified by coating and calendering processes to reduce surface roughness and electrical resistance of inkjet-printed UHF RFID antennas. The composition of coatings, the main component which included aluminum oxide pigment, had an influence on the surface roughness, the surface pore content and the electrical resistance of the inkjet-printed UHF RFID antennas on coated papers. Papers coated with a mixture containing $25 \%$ polyvinyl alcohol binder in combination with the cationic polymer PDADMAC without glyoxal crosslinker had the lowest surface roughnesses and the lowest electrical resistances of the inkjet-printed antennas. As the coating basis weight increased, the electrical resistance of the antennas increased. Reduction of the electrical resistance of the antennas was achieved after calendering coated paper. The design of the antennas had a significant effect on their electrical resistance, which increased with the length of the antenna.
\end{abstract}

KEYWORDS: Paper, coating, calendering, surface roughness, inkjet printing, RFID antenna, electrical resistance.

\section{INTRODUCTION}

The popularity of radio frequency identification (RFID) has lately increased significantly, particularly in relation to printing of antennas on paper substrates. Low-cost and recyclable paper substrates are being considered for various printed applications. RFID technology is dedicated to contactless identification of various objects. It is applied in the industry, trade, security and in almost all other socioeconomic areas. The applied RFID components have to meet various technological, environmental and, above all, low-cost requirements, because they must be integrated with various objects that are characterized by different physical properties.

RFID is an automated identification technology that consists of a reader, a reader antenna 
and a tag which consists of a tag antenna and a chip. The antenna is relatively large compared to the chip size. RFID technology uses radio waves to transfer the information between the reader and the tag at distances of $2 \mathrm{~cm}$ up to $20 \mathrm{~m}$. The RFID tag, depending on the type, may operate at different frequencies: low (LF: $125 \mathrm{kHz}$ or $134 \mathrm{kHz}$ ), high (HF: $13.56 \mathrm{MHz}$ ) or ultrahigh radio frequency ranges (UHF: 860-960 MHz).

Conventional production of RFID antennas was realized by etching of metallized plastic, which is costly and environmentally unfriendly, so there is an effort to produce printed RFID antennas. Different printing technologies are used: flexography, gravure printing, inkjet printing, screen and thermal transfer printing. Different printing technologies enable different accuracy, resolution and conductive layer thickness.

Printed antennas are usually applied to different plastic films (Chin et al. 2008, Janeczek 2010, Arazna et al. 2017) or paper substrates (Melampi et al. 2007, Rida et al. 2009, Lakafosis et al. 2010, Xi et al. 2011, Zichner and Bauman 2011, Öhlund and Andersson 2012, Bollström and Toivakka 2013, Kavčič et al. 2014, He et al. 2016). There are many aspects of paper that make it an excellent candidate for a low-cost and environmentally-friendly substrate for printed electronics. The different types of paper have various density, coating, thickness, texture and dielectric properties.

Modifications of paper substrates and printing processes are required in order to obtain working electronic devices. The paper substrate for printed electronic must be compatible with all phases of the tag manufacturing process such as good printability and resistance of the sintering process and no shrinkage without cracking. Another important factors are the electrical properties of the printed paper substrate over a wide range of frequencies, temperature and humidity.

Paper has a rougher surface compared to the plastic film. Irregular surfaces and structural properties of conventional papers require higher ink consumption, allowing them to be used only for electronic components with lower resolution or print quality requirements. In order to improve printability, research of label and packaging paper production technology is aimed at improving surface smoothness and absorption properties.

Coating and calendering processes can be used to modify the paper surface. The paper surface is usually smoothed with a dispersion coating consisting of mineral pigments and organic binders. The smoothness of the paper surface depends on composition of coatings, the amount and layers of the coating and the final surface finish. Depending on the composition of the coatings, properties such as smoothness, porosity, permeability and surface energy as well as optical properties (brightness and opacity) can be varied. The surface properties of papers can be adjusted at the same time to achieve the desired functional properties, such as water, oil and grease resistance, low vapor and gas permeability, and flame retardation.

Nanoscale coating techniques including layer-by-layer and liquid flame spray coating have been studied that allow surface functionalization with significantly reduced coating amounts. Controlling the surface properties of nanoparticles is essential to achieve good performance in electronic applications (Perelaer et al. 2010).

Knowledge of the interactions between functional materials formulated and applied on paper as inks makes possible to create a paper-based substrate that can be used for printed electronics. The surface pore volume and pore size can be optimized for a given printing process and ink through a choice of pigment type and coating layer thickness. The printing of functional inks on paper offers the possibility of light weight, thin film electronic devices that increase the value of the product and reduce the overall cost of implementation. One application for such technology is the printing of RFID antennas directly to packaging materials. 
Pigment shape, size and size distribution have a significant impact on coating coverage. The pigment structure and particle shape are the key parameters that control the coverage, porosity and ink absorption of the coated substrate. The binder is an important part of the coating formulation because it not only imparts strength to the coating layer, but it also impacts the porosity, ink absorption, and optical properties of the coating (Lehtinen 2000).

Colour gamut area, black ink optical density, print sharpness, porosity, surface wetting by water and inkjet ink, base fibrous matrix and surface roughness were used for evaluation of inkjet print quality. Inkjet ink contact angle is a suitable parameter for prediction of colour gamut area of inkjet paper (Gigac et al. 2015). Coating base papers with silica-based coating resulted in the best colour gamut area, print sharpness and fastness to water because of good water and cyan ink wettability of surface. Papers coated with calcium carbonate did not achieve such colour gamut area and sharpness as silica coated paper. Paper coated with coating colour of film-forming polyvinyl alcohol as binder had better colour gamut area compared to cationic starch (Gigac et al. $2016 \mathrm{a}, \mathrm{b})$.

Inkjet printing is a digital and non-contact technique that is almost free of chemical waste and doesn't require special facilities for its use. Furthermore, the possibility of using well known substrates like paper or polymer film enables flexible, cheap and disposable device. It is ideal for fast prototyping and promises high throughput, low cost and improved environment-friendliness (Albrecht et al. 2016). The printed ink layer is thin and the particles in the ink must be very small and uniformly spread.

The inks used for electronic printing are typically made of copper and/or silver nanoparticles due to their high electrical conductivity in some kind of organic solvent and polymer coating (Dearden et al. 2004, Perelaer et al. 2006, Park et al. 2007). The polymer coating of the metal nanoparticles serves as a stabilizer the dispersed particles in the ink to prevent them from coalescing, merging into larger aggregates, and clogging the print head nozzles in the inkjet printer. Polyelectrolytes combining both electrostatic and steric stabilization effect are in general very effective stabilizers. Examples of stabilizers of Ag nanoparticles are poly(N-vinyl2-pyrrolidone), carboxylmethylcellulose sodium salt, polynaphthene sulfonate formaldehyde condensate, Daxad 19, Disperbyk, which is a high molecular weight block copolymer with acidic affinic groups and poly(acrylic acid) salts (Kamyshny et al. 2011).

The printing of the conductive elements with metallic nanoparticle inks must be followed by an additional sintering step, usually achieved by heating to elevated temperatures. Without sintering the printed trace of the metallic particles, nano-silver ink acts as an insulator in the dried state. Sintering is the material atomic diffusion process driven by the reduction of interfacial energy between the metal particles. Densification only occurs when the distance between the centers of the particles change. Sintering not only renders the printed ink tracks conductive, but also affects the physical and electrical properties of the metal nanoparticle tracks. One major property that is linked to sintering is electrical resistance. With lower sintering temperatures, the electrical resistivity of the printed metal nanoparticle tracks can be up to 2 to 3 times lower than its theoretical bulk resistivity (Greer and Street 2007).

The silver nanoparticle-based ink for printing of electronics has been developed, having a built-in sintering mechanism, which is triggered during drying of the printed pattern (Grouchko et al. 2011). This ink is mainly a dispersion of electrosterically stabilized silver nanoparticles, together with a low concentration of destabilizer, which acts as a sintering agent and comes into action only upon drying of dispersion. The sintering agent, which can be a simple electrolyte such as sodium chloride, destabilizes the silver nanoparticles and leads to their close contact. The chloride ions replace and detach the anchoring groups of the polymeric stabilizer 
from the nanoparticles surface and thus enable their coalescence and sintering. Fig. 1 illustrates the sintering process of silver nanoparticles triggered by changing the chloride ions concentration.
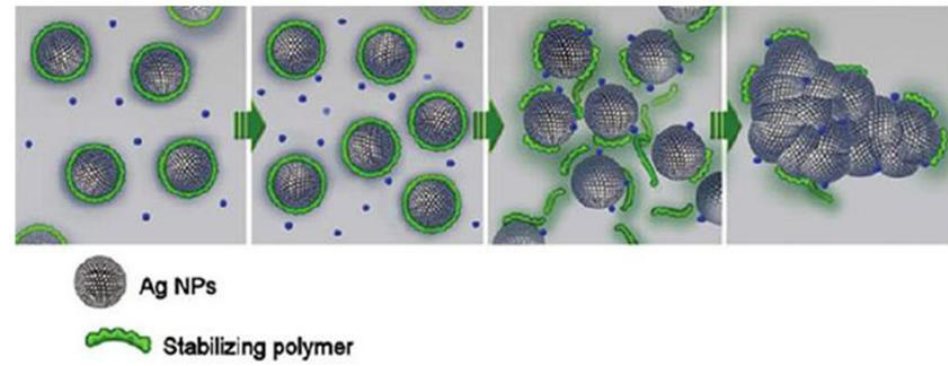

Source: Grouchko et al. 2011.

Fig. 1: Schematic illustration of stabilizer detachment, which leads to the nanoparticle sintering (the green represent the polymeric stabilizer, the blue sphere represents the sintering agent).

In this study, the effect of coating compositions on surface roughness, surface pore content and electrical resistance of inkjet-printed UHF RFID antennas on experimentally coated and calendered papers were investigated. The electrical resistance of the antennas on the paper substrates was compared to the electrical resistance of the antennas on the PET film.

\section{MATERIAL AND METHODS}

\section{Materials}

Base papers for coating experiments were commercial calendered double-sided coated offset papers (A and $\mathrm{B})$.

Polyethylene terephthalate (PET) film NOVELE from NovaCentrix was used as a reference substrate for printing UHF RFID antennas.

Inkjet ink METALON JS-B25P containing Ag nanoparticles from NovaCentrix.

Antennas design for inkjet printing:

UHF RFID antenna 1 - Type DogBone, from the Smartrac division of the company Avery Dennison, compatible with chip NXP UCODE G2iL/iM or Impinj Monza 5.

UHF RFID antenna 2 - Type undefined,

UHF RFID antenna 3 - Type AD-227m5 from the company Avery Dennison, compatible with chip Impinj Monza 5.

Coatings compositions: Aerodisp W 630 (A12O3), Mowiol 6-88 (polyvinyl alcohol - PVOH), Cartabond TSI (glyoxal), polydiallyldimethylammonium chloride (PDADMAC), Despumol (defoamer), $\mathrm{KCl}$ - sintering agent, glucose and ascorbic acid - reducing agents.

\section{Methods}

Coating of base papers $\mathrm{A}$ and $\mathrm{B}$ with aluminum oxide aquous dispersions was performed using bar with a wound wire of different thickness (T1 to T5).

Calendering of papers was performed by two passes in a laboratory calender Kleinewefers at a pressure of $260 \mathrm{kPa}$ and a metal roller temperature of $80^{\circ} \mathrm{C}$.

Wettability was determined as contact angle of water on surface of base and coated papers by 
"Sessile drop" method using the tensiometer OCA 35 (Dataphysics Instruments).

Surface rougness of paper substrates was determined as optical variability of surface (OVS) using photoclinometry. Surface roughness $\mathrm{OVS}_{\mathrm{CLINO}}$ was calculated as arithmetic mean of grey levels variation coefficients from machine direction $\left(\mathrm{OVS}_{\mathrm{CLINO}}\right)_{\mathrm{MD}}$ and cross direction $\left(\mathrm{OVS}_{\mathrm{CLINO}}\right)$ $\mathrm{CD}$ histograms. The surface of paper substrates was displayed by Nikon Coolpix E4500 CCD camera in macro mode. Specification of scanned images: $10^{\circ}$ inclined illumination in machine direction (MD) and cross direction (CD), magnification X4, image size $2272 \times 1704$ pixels. These images can be transformed into a surface map with different heigh levels. From these images, the optical variability of surface was determined, which is defined by the light and dark (shadowed) image areas. ImageJ software was used for image analysis of paper substrate surface. It expresses the surface roughness in a similar way as the roughness parameter $\mathrm{Rq}$ (average surface root means squared roughness), described in ISO 4287 standard (Gigac et al. 2013).

Surface pore content of coated paper surface was determined by high magnification scanning electron microscopy (SEM). The coated paper surfaces were covered with gold in the BALZER SCD 040 sputtering device in 0.15 bar vacuum for a period of $40 \mathrm{~s}$ with $50 \mathrm{~mA}$ electric current. JEOL 760F scanning electron microscope equipped with Schottky thermo emission cathode (thermal FEG - W platting by $\mathrm{ZrO}_{2}$ ) and with energy and wavelength dispersive spectrometer (Oxford Instruments) was used. Specification of scanned images: magnification X10000, accelerating voltage $2 \mathrm{kV}$, work distance $7.9 \mathrm{~mm}$, image size 2530 x 1890 pixels, image resolution $0.005 \mu \mathrm{m} /$ pixel. The software of harmonic and fractal analysis (HarFA 5.3) by couting method for image analysis was used (Gigac et al. 2013).

Antennas printing was performed with a EPSON STYLUS $\mathrm{C} 88^{+}$piezoelectric inkjet printer. Sintering (curing) of inkjet-printed antennas was caried out at downforce of $75 \mathrm{kPa}$ of the metal plate heated to $130^{\circ} \mathrm{C}$ for 15 seconds.

Electrical resistance of the printed antennas was measured using a multimeter UNIT-T, Model UT70B.

Viscosity of the aqueous coating composition was determined by the standard test method ASTM D 1200 - 10 (2018) by Ford Viscosity Cup.

\section{RESULTS AND DISCUSSION}

The aim of base paper coating and calendering was to improve their surface smoothness and the quality of the inkjet-printed UHF RFID antennas in order to achieve the highest electrical conductivity, respective, the lowest electrical resistance. With lower antenna resistance, a higher reading range is achieved. The overall coating result is determined by the composition and properties of the coating dispersions. The proper representation of binders and other excipients is required, a perfect dispersion of filler particles in which each particle is separated and wetted by the binder. Concentration, viscosity and rheological properties of the coating dispersions are also important.

Base papers $\mathrm{A}$ and $\mathrm{B}$ were experimentally coated with top coatings, whose basic component was an aqueous dispersion of hydrophilic micronized pigment $\mathrm{Al}_{2} \mathrm{O}_{3}$ with polyvinyl alcohol $(\mathrm{PVOH})$ as a binder, glyoxal as a crosslinking agent, and a defoamer. In addition to these components, polydiallyldimethylammonium chloride (PDADMAC) was added as a high charge density cationic polymer, $\mathrm{KCl}$ as a sintering agent, glucose and ascorbic acid as reducing agents.

The top coating compositions used in experiments E1 to E7 for coating base papers A and $\mathrm{B}$ are presented in Tab. 1. Viscosity of the aqueous coating dispersions measured with the Ford 4 Cup was around $14 \mathrm{~s}$, the solids content of dispersions ranged from 10 to $11 \%$ and the $\mathrm{pH}$ was 
around 4.5. The coating basis weight on the paper varied depending on the thickness of the wound wire on the used bar (T1 to T5) when coating.

Tab. 1: Composition of top coatings in experiments 1 to 7.

\begin{tabular}{|l|c|c|c|c|c|c|c|}
\hline \multirow{2}{*}{ Coating composition } & \multicolumn{7}{|c|}{ Experiment no. } \\
\cline { 2 - 9 } & E1 & E2 & E3 & E4 & E5 & E6 & E7 \\
\hline $\mathrm{Al}_{2} \mathrm{O}_{3}$ - Aerodisp 630 (\%) & 100 & 100 & 100 & 100 & 100 & 100 & 100 \\
\hline PVOH - Mowiol 6-88 (\%) & 25 & 25 & 15 & 15 & 15 & 15 & 15 \\
\hline Glyoxal - Cartabond TSI (\%) & 2 & 0 & 2 & 2 & 3 & 3 & 3 \\
\hline PDADMAC - cationic polymer (\%) & 5 & 5 & 0 & 0 & 0 & 0 & 0 \\
\hline Despumol - defoamer (\%) & 0.01 & 0.01 & 0.01 & 0.01 & 0.01 & 0.01 & 0.01 \\
\hline $\mathrm{KCl}$ - sintering agent (\%) & & & & & 0.2 & 0.3 & 0.3 \\
\hline Glucose - reducing agent (\%) & & & & 0.3 & & & 0.3 \\
\hline Ascorbic acid - reducing agent (\%) & & & & & 0.3 & 0.4 & \\
\hline
\end{tabular}

\section{Influence of coating compositions on surface roughness and surface pore content}

The purpose of coating hydrophobic base papers with a contact angle of more than $90^{\circ}$ was to increase the wettability and smoothness of the paper surfaces and improve inkjet printing quality using ink with silver nanoparticles. The formulation of coating compositions was based on the results of our previous work (Gigac et al. 2014, Gigac et al. 2015). Optimal inkjet printing quality is achieved if the paper surface is capable of rapidly absorbing solvent (water) from the ink and $\mathrm{Ag}$ nanoparticles remain anchored to the surface. This was achieved with coating pigments based on aluminum oxide, silica and precipitated calcium carbonate. The presence of large pores allowed rapid absorption of the ink solvent. The large surface area of pigment with the fine pores in combination with the cationic polymer PDADMAC allowed the fixation of $\mathrm{Ag}$ nanoparticles on the surface. In addition, the smoothed surface of the coated paper allowed the inkjet ink to spread evently.

The surface roughnesses and surface pore contents of uncoated and coated papers A and $\mathrm{B}$ with top coatings are listened in Tab. 2. The influence of the coating basis weight and the calendering process on the surface roughness is presented as well. The compositions of top coatings are in Tab. 1 . The surface roughness of paper was determined as the optical variability of the surface using the photoclinometric method and the surface pore content was determined by SEM microscopy. The surface roughness of base paper B was lower (6.5\%) than base paper A (7.8\%). The surface roughnesses of coated papers A were reduced to values of 5.3 to $6.1 \%$, which represents a reduction of $22-32 \%$. The surface roughnesses of coated papers B reduced to of 5.5 to $6.2 \%$, this represents a reduction of $5-15 \%$. The surface roughnesses decreased more after coating of base paper A than base paper B. The surface roughness was reduced more after coating of base paper with higher surface roughness.

Increased coating basis weight on both types of coated papers increased the surface roughness or reduced the surface smoothness, respectively. The surface roughness of coated paper A-E6-T2 with the coating basis weight of $2.4 \mathrm{~g} \cdot \mathrm{m}^{-2}$ was higher (6.1\%) than the surface roughness of coated paper A-E6-T1 with half coating basis weight (5.6\%). Similarly, the surface roughness of coated paper B-E7-T4 with a coating basis weight of $4.8 \mathrm{~g} \cdot \mathrm{m}^{-2}$ was higher $(6.0 \%)$ than the surface roughness of coated paper B-E7-T2 with half coating basis weight (5.7\%).

After calendering, the surface roughness of both coated paper types was reduced. The surface roughness of coated paper A-E7-T4 decreased from 5.7 to 5.1\% CAL-A-E7-T4. Similarly, the surface roughness of coated paper B-E7-T4 decreased from 6.0 to 5.4\% CAL-B-E7-T4. 
Vol. 65 (1): 2020

The effect of base papers A and B coating as well as the calendering of coated papers on the surface pore content is presented in Tab. 2. The surface pore content of base paper B (19.4\%) was higher than that of base paper A (15.4\%). After coating, the surface pore content increased for both types of base papers. The surface pore contents of coated papers A were in the range of $20.9 \%$ to $23.9 \%$, which represents an increase of $36-55 \%$ after coating. The coated papers B had surface pore contents in the range of $22.6 \%$ to $25.0 \%$, which represents an increase of $16-29.0 \%$ after coating.

Tab. 2: Effect of base papers $A$ and $B$, coating compositions and calendering of coated papers on surface roughness and surface pore content.

\begin{tabular}{|c|c|c|c|c|}
\hline \multirow{2}{*}{$\begin{array}{c}\text { Coating } \\
\text { experiments }\end{array}$} & \multicolumn{2}{|c|}{ Base paper A } & \multicolumn{2}{c|}{ Base paper B } \\
\cline { 2 - 5 } & $\begin{array}{c}\text { Surface } \\
\text { roughness (\%) }\end{array}$ & $\begin{array}{c}\text { Surface } \\
\text { pore content (\%) }\end{array}$ & $\begin{array}{c}\text { Surface } \\
\text { roughness (\%) }\end{array}$ & $\begin{array}{c}\text { Surface } \\
\text { pore content (\%) }\end{array}$ \\
\hline Base paper & 7.8 & 15.4 & 6.5 & 19.4 \\
\hline E1-T1 & 5.7 & 22.3 & 6.0 & 23.0 \\
\hline E2-T1 & 5.4 & 20.9 & 5.5 & 22.6 \\
\hline E3-T5 & 5.4 & 22.4 & 5.7 & 23.6 \\
\hline E4-T5 & 5.3 & 21.1 & 5.6 & 24.5 \\
\hline E5-T4 & 6.0 & 23.5 & 6.2 & 24.9 \\
\hline E6-T1 & 5.6 & 23.4 & 5.7 & 25.0 \\
\hline E6-T2 & 6.1 & 23.0 & 6.2 & 24.2 \\
\hline E7-T2 & 5.4 & 23.9 & 5.7 & 24.5 \\
\hline E7-T4 & 5.7 & 22.9 & 6.0 & 23.5 \\
\hline CAL-E7-T4 & 5.1 & 22.4 & 5.4 & 22.9 \\
\hline
\end{tabular}

The quality of coating depends on the base paper, the coating composition and the coating basis weight. An inappropriate combination of base paper and coating composition causes cracking of surface already also even at lower coating basis weights.

The surface roughness of the base paper had an effect on the surface roughness of the coated papers. After coating a base paper with a higher surface roughness, the surface roughness decreased more compared to a base paper with a lower surface roughness. After coating of base papers with the same coating compositions, the surface roughnesses of the coated papers A were lower than that of coated papers B.

Similarly as the surface roughness also the surface pore content of the base paper had an influence on the surface porosity of the coated papers. After coating a base paper with a lower surface pore content, the surface pore content increased more compared to a base paper B with a higher surface pore content. After coating base papers with the same coating compositions, the surface pore contents of the coated papers A were lower than the coated papers B.

\section{Influence of coating compositions on electrical resistance of UHF RFID antennas}

UHF RFID antennas were inkjet-printed on base papers A and B, coated papers and PET film. The designs of antennas are presented in Fig. 2. The electrical resistance of inkjet-printed antennas was measured after drying and sintering as the antennas must be conductive. 


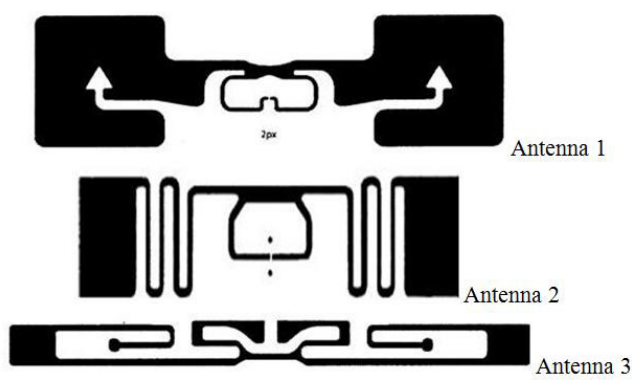

Fig. 2: UHF RFID antennas designs.

Figs. 3 and 4 compare the electrical resistances of UHF RFID inkjet-printed antennas on base and coated papers with antennas printed on commercial PET film, which is a suitable substrate for printing UHF RFID antennas. The top coating compositions used in experiments (E1 to E7) are shown in Tab. 1. Antenna 1 printed on PET film had an electrical resistance of $2.5 \Omega$, antenna 2 of $20 \Omega$, and antenna 3 of $8.5 \Omega$. The antennas printed on base papers $A$ and $B$ had significantly higher electrical resistances compared with antennas printed on PET film, what is related to the hydrophobic and rough surface of the paper. The antennas printed on base paper A had lower electrical resistances (Fig. 3) than the antennas on base paper B (Fig. 4).

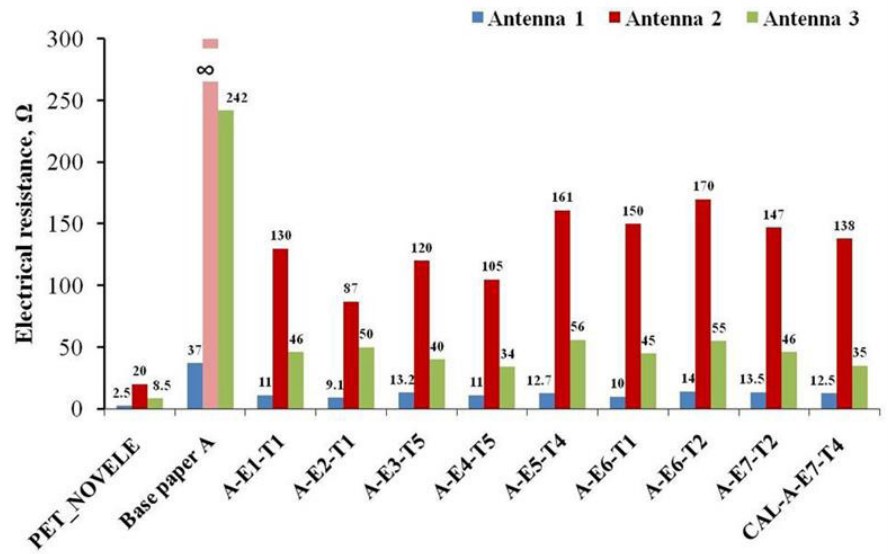

Fig. 3: Comparison of electrical resistances of inkjet-printed UHF RFID antennas on base paper A and coated papers with antennas printed on PET film.

After coating of base papers $\mathrm{A}$ and $\mathrm{B}$, the electrical resistance of the antennas decreased significantly (Figs. 3 and 4) but did not reach the level of the antennas on the PET film. Reducing the electrical resistance of the antennas allowed a hydrophilic and less rough surface of the coated papers compared to base paper. A comparison of the electrical resistances of the antennas shows that in this case, the electrical resistances of the antennas printed on coated papers A were also lower than the electrical resistances of the antennas printed on coated papers $B$.

Antennas printed on A-E2-T1 and B-E2-T1 papers coated with the composition containing $25 \%$ binder $\mathrm{PVOH}$ in combination with a cationic polymer PDADMAC without of glyoxal crosslinking agent had the lowest electrical resistance. The beneficial effect of the cationic 
polymer PDADMAC on the electrical resistance of antennas printed with Ag nanoparticle ink has also been confirmed in the work (Magdassi et al. 2010).

The electrical resistances of antennas printed on papers A-E1-T1 and B-E1-T1 coated with the composition containing $2 \%$ glyoxal were higher than electrical resistances antennas printed on papers A-E2-T1 and B-E2-T1 coated with the composition without glyoxal (Figs. 3 and 4).

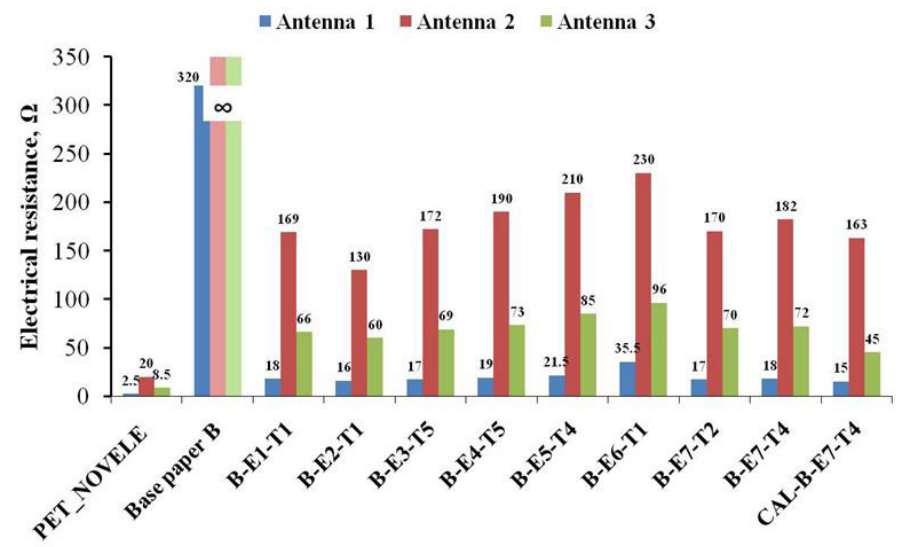

Fig. 4: Comparison of electrical resistances of inkjet-printed UHF RFID antennas on base paper B and coated papers with antennas printed on PET film.

The addition of sintering agent $\mathrm{KCl}$ and reducing agents glucose or ascorbic acid to the coating compositions (Tab. 1, E3 to E7) had no significant effect on the electrical resistances of the antennas printed on coated papers (Figs. 3 and 4).

The results show that antenna design has a significant effect on their electrical resistance. Antenna 1 had the lowest electrical resistance, then antenna 3, while the electrical resistance of the meander antenna 2 was considerably higher related to the longest antenna length. In Fig. 5 is an illustration of the measuring points on the antenna 2 .

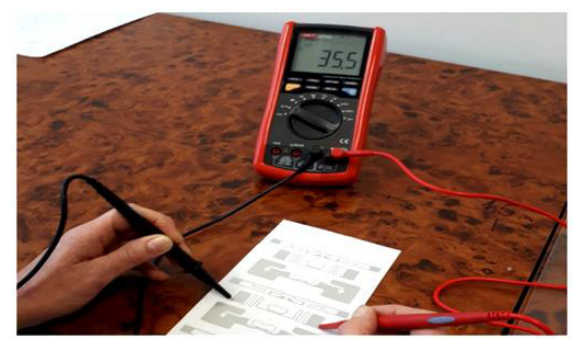

Fig. 5: Measurement of electrical resistance of UHF RFID antennas with UNIT-T multimeter, model UT70B.

The effect of the coating basis weight on the electrical resistances of the inkjet-printed antennas was determined based on the electrical resistances of the antennas printed on coated papers A-E6-T1 and A-E6-T2 (Fig. 3). Antennas printed on coated paper A-E6-T1 with the coating basis weight of $1.4 \mathrm{~g} \cdot \mathrm{m}^{-2}$ had lower electrical resistances than antennas printed on paper 
A-E6-T2, which had twice higher coating basis weight. Analogous results were obtained for coated papers B-E7-T2 and B-E7-T4 (Fig. 4). The electrical resistances of the antennas printed on coated paper B-E7-T2 with the coating basis weight of $2.8 \mathrm{~g} \cdot \mathrm{m}^{-2}$ were lower than the electrical resistances of the antennas printed on coated paper B-E7-T4 with a coating basis weight of $5.6 \mathrm{~g} \cdot \mathrm{m}^{-2}$.

The calendering process of coated papers had a positive effect on the electrical resistance of inkjet-printed antennas. Antennas printed on calendered coated paper CAL-A-E7-T4 had lower electrical resistances than antennas printed only on coated paper A-E7-T4 (Fig. 3). Similar results were obtained for antennas printed on calendered coated paper CAL-B-E7-T4, these ones had lower electrical resistances than antennas printed only on coated paper B-E7-T4 (Fig. 4).

\section{CONCLUSIONS}

Paper substrates are more advantageous for printing of UHF RFID antennas than plastic films as they are recyclable and several times cheaper. However, the surface of conventional papers is not suitable for printed electronics, as they have a rougher surface compared to plastic film, but their advantage is higher rigidity and low expansion. Reducing the surface roughness and hence the electrical resistance of the inkjet-printed antennas on papers was achieved by coating and subsequent calendering processes.

The properties of the base paper and the composition of the coatings, the main component of which was the aluminum oxide pigment, had an influence on the surface roughness, the surface pore content and the electrical resistance of the inkjet-printed antennas on the coated papers. Antennas printed on coated paper with the composition, which contained 25\% $\mathrm{PVOH}$ binder in combination with the cationic polymer PDADMAC without glyoxal crosslinker, they had the least electrical resistance. The addition of sintering agent $\mathrm{KCl}$ and reducing agents glucose or ascorbic acid to the coating compositions had no significant effect on the electrical resistances of inkjet-printed UHF RFID antennas. Electrical resistance of the antennas was higher for antennas printed on paper with a higher coating basis weight.

Electrical resistances of inkjet printed UHF RFID antennas decreased after calendering of coated papers, however, as the coating basis weight on paper increased, electrical resistance of the antennas increased.

The design of inkjet-printed UHF RFID antennas on paper substrates had a significant effect on their electrical resistance, which depends on the length of the antenna and is strongly influenced by the geometric dimensions of its narrowest part.

\section{ACKNOWLEDGMENT}

The achieved research results originated during the solution of the applied research project titled "Research of technology of paper smart packaging production". The project was supported by the Ministry of Education, Science, Research and Sports of Slovak Republic in frame of incentives provided for research and development from the national budget based on law no. 185/2009 and addition to law no. 595/2003 about wage taxes with later guidelines in law 40/2011. 


\section{REFERENCES}

1. Albrecht, A., Rivadeneyra, A., Salmerón, J., Abdellah, A., Lugli, P., 2016: Inkjet printing and photonic sintering of silver and copper oxide nanoparticles for ultra-low-cost conductive patterns. Journal of Materials Chemistry C (4): 3546-3554.

2. Arazna, A., Janeczek, K., Futera, K., 2017: Mechanical and thermal reliability of conductive circuits inkjet printed on flexible substrates. Circuit World 43(1): 9-12.

3. Bollström, R., Toivakka, M., 2013: Paper substrate for preinted functionality. 15th Fundamental Research Symposium. Cambridge, September 2013, Pp 945-966.

4. Dearden, A., Smith, P., Shin, D.Y., Reis, N., Derby, B., Paul O’Brien, P., 2004: A low curing temperature silver ink for use in ink-jet printing and subsequent production of conductive tracks. Macromolecular Rapid Communications 26(4): 315-318.

5. Gigac, J., Kasajová, M., Maholányiová, M., Stankovská, M., Letko, M., 2013: Prediction of surface structure of coated paper and of ink setting time by infrared spectroscopy. Nordic Pulp \& Paper Research Journal 28(2): 274-281.

6. Gigac, J., Stankovská, M., Letko, M., Opálená, E., 2014: The effect of base paper properties on inkjet print quality. Wood Research 59(5): 717-730.

7. Gigac, J., Stankovská, M., Fišerová, M., Opálená, E., 2015: Improvement of inkjet print quality via hydrophylic polymers and base paper. Wood Research 60(5): 739-746.

8. Gigac, J., Stankovská, M., Opálená, E., Pažitný, A., 2016a: The effect of pigments and binders on inkjet print quality. Wood Research 61(2): 215-226.

9. Gigac, J., Stankovská, M., Pažitný, A., 2016b: Influence of the coating formulations and base papers on inkjet printability. Wood Research 61(6): 915-926.

10. Greer, J.R., Street, R.A., 2007: Thermal Cure effects on electrical performance of nanoparticle silver inks. Acta Materialia 55 (18): 6345-6349.

11. Grouchko, M. Kamyshny, A., Mihailescu, C.F., Anghel, D.F., Magdassi, S., 2011: Conductive inks with a „built-in“ mechanism that enables sintering at room temperature. ACS Nano 5(4): 3354-3359.

12. He, H., Sydänheimo, L., Virkki, J., Ukkonen, L., 2016: Experimental study on inkjetprinted passive UHF RFID tags on versatile paper-based substrates. International Journal of Antennas and Propagation, Article ID 9265159, 8 pp.

13. Chin, K.C., Tsai, C.H., Chang, L.C., Wei, C.L., Chen, W.T., Chen, C.S., Lai, S.J., 2008: Design of flexible RFID tag and rectifier circuit using low cost screen printing process. IPC - IPC Printed Circuits Expo, APEX and the Designers Summit 2008.

14. Janeczek, K., 2010: Performance of RFID tag antennas printed on flexible substrates. XII International PhD Workshop, Wisla, Poland.

15. Kamyshny, A., Steinke, J., Magdassi, S., 2011: Metal-based inkjet ink for printed electronics. The Open Applied Physics Journal (4): 19-36.

16. Kavčič, U., Pivar, M., Dokič, M., Svetec, D.G., Pavlovič, L., Muck, T., 2014: UHF RFID tags with printed antennas on recycled papers and cardboards. Materials and Technology 48(2): 261-267.

17. Lakafosis, V, Rida, A., Vyas, R., Li, Y., Nikolaou, S., Tentzeris, M.M., 2010: Progress towards the first wireless sensor networks consisting of inkjet-printed, paper-based RFIDenabled sensor tags, Proceedings of the IEEE 98 (9): 1601-1609.

18. Lehtinen, E., 2000: Pigments coating and surface sizing of paper. Papermaking Science and Technology, Vol. 11, TAPPI Press, 2000. 
19. Merilampi, S., Ukkonen, L., Sydanheimo, L., Ruuskanen, P., Kivikoski, M., 2007: Analysis of silver ink bow-tie RFID tag antennas printed on paper substrates. International Journal of Antennas and Propagation, Article ID 90762, 9 pp.

20. Öhlund, T., Andersson, M., 2012: Effect of paper on electrical conductivity and pattern definition for silver nanoparticle inkjet ink. Proceedings LOPE-C, January 2012, Pp. 115-119.

21. Park, B.K., Dongjo Kim, D., Sunho, J., Moon, J., Jang Sub Kim, J.S., 2007: Direct writing of copper conductive patterns by ink-jet printing. Thin Solid Films 515 (2007): 7706-7711.

22. Perelaer, J., de Gans, B.J., Ultrich S. Schubert, U.S., 2006: Ink-jet printing and microwave sintering of conductive silver tracks. Advanced Materials 18(16): 2101-2104.

23. Rida, A., Li, Y., Vyas, R., Tentzeris, M.M., 2009: Conductive inkjet-printed antennas on flexible low-cost paper-based substrates for RFID and WSN applications. Antennas and Propagation Magazine, IEEE 51 (3): 13-23.

24. Xi, J., Zhu, H., Ye, T.T., 2011: Exploration of printing-friendly RFID antenna designs on paper substrates. 2011 IEEE International Conference on RFID, Pp 38-44.

25. Zichner, R., Baumann, R.R., 2011: Communication Quality of Printed UHF RFID transponder antennas. LOPE-C, Messe Frankfurt, Germany, Pp 361-363.

\author{
Juraj Gigac*, Mária Fišerová, Maroš Kováč, Monika Stankovská \\ Pulp and Paper Research Institute \\ Dúbravská Cesta i4 \\ 84I O4 BratisLava \\ Slovak Republic \\ *Corresponding author: gigac@vupc.sk
}

